\title{
Targeted Chromatin Capture (T2C): a novel high resolution high throughput method to detect genomic interactions and regulatory elements
}

Petros Kolovos ${ }^{1}$, Harmen JG van de Werken ${ }^{1}$, Nick Kepper ${ }^{2}$, Jessica Zuin ${ }^{1}$, Rutger WW Brouwer ${ }^{3}$, Christel EM Kockx ${ }^{3}$, Kerstin S Wendt ${ }^{1}$, Wilfred FJ van IJcken ${ }^{3}$, Frank Grosveld ${ }^{1 *}$ and Tobias A Knoch ${ }^{1 *}$

\begin{abstract}
Background: Significant efforts have recently been put into the investigation of the spatial organization and the chromatin-interaction networks of genomes. Chromosome conformation capture (3C) technology and its derivatives are important tools used in this effort. However, many of these have limitations, such as being limited to one viewpoint, expensive with moderate to low resolution, and/or requiring a large sequencing effort. Techniques like $\mathrm{Hi}-\mathrm{C}$ provide a genome-wide analysis. However, it requires massive sequencing effort with considerable costs. Here we describe a new technique termed Targeted Chromatin Capture (T2C), to interrogate large selected regions of the genome. T2C provides an unbiased view of the spatial organization of selected loci at superior resolution (single restriction fragment resolution, from 2 to $6 \mathrm{kbp}$ ) at much lower costs than $\mathrm{Hi}-\mathrm{C}$ due to the lower sequencing effort.

Results: We applied T2C on well-known model regions, the mouse $\beta$-globin locus and the human H19/IGF2 locus. In both cases we identified all known chromatin interactions. Furthermore, we compared the human H19/IGF2 locus data obtained from different chromatin conformation capturing methods with $\mathrm{T} 2 \mathrm{C}$ data. We observed the same compartmentalization of the locus, but at a much higher resolution (single restriction fragments vs. the common $40 \mathrm{kbp}$ bins) and higher coverage. Moreover, we compared the $\beta$-globin locus in two different biological samples (mouse primary erythroid cells and mouse fetal brain), where it is either actively transcribed or not, to identify possible transcriptional dependent interactions. We identified the known interactions in the $\beta$-globin locus and the same topological domains in both mouse primary erythroid cells and in mouse fetal brain with the latter having fewer interactions probably due to the inactivity of the locus. Furthermore, we show that interactions due to the important chromatin proteins, Ldb1 and Ctcf, in both tissues can be analyzed easily to reveal their role on transcriptional interactions and genome folding.
\end{abstract}

Conclusions: T2C is an efficient, easy, and affordable with high (restriction fragment) resolution tool to address both genome compartmentalization and chromatin-interaction networks for specific genomic regions at high resolution for both clinical and non-clinical research.

Keywords: Chromatin conformation capture, Long range interactions, Enhancers, Promoters

\footnotetext{
*Correspondence: f.grosveld@erasmusmc.nl; TA.Knoch@taknoch.org

'Department of Cell Biology, Erasmus MC, Dr. Molewaterplein 50, 3015GE

Rotterdam, The Netherlands

Full list of author information is available at the end of the article
} 


\section{Background}

A number of recent studies have shown that the genome is organized in self-associating domains [1] that are separated by linker regions. These so-called 'topological domains' or 'topological associated domains' generally range from 300 kilobasepairs (kbp) to 1 megabasepairs (1 Mb) and consist of a series of different types of chromatin loops in agreement with earlier models of the genome ([2] and references therein).

One loop is defined as two distant chromatin regions coming, spatially, into close proximity (interact with each other), thereby creating DNA loops. Such 'long-range interactions' have been first observed between promoters and distant enhancers $([3,4]$ and references therein) and can bring DNA elements together that are separated by a large distance on the linear DNA strand ([5,6] and references therein). These regulatory elements (enhancers or silencers) are short sequences containing several binding sites for transcription factors, which regulate the activation (reviewed in [7]) repression (reviewed in [8]) genes and their subsequent transcription (reviewed in [9]). In the linear genome the distance between enhancer(s) and gene can be quite large, for example, the sonic hedgehog (shh) enhancer is located about $1 \mathrm{Mb}$ away from its target gene Shh [10]. Changes or differences within these elements and their interaction with genes can be responsible for changes in gene expression [11], causing intrinsic differences between individuals, disease susceptibility, and disease progression.

A number of chromatin loops are thought to be purely structural, that is, to enable the folding of the genome creating distinct topological domains, while other loops have a function in the expression of genes. Loops of the latter type are frequently found within topological domains, but are less frequently observed between different topological domains [1,12]. These regulatory chromatin loops change and depend on a large number of proteins including Ctcf [13], cohesin [14], and a series of transcription factors [15-18], which are mostly involved in the transcriptional regulation of genes within the domain.

The recent refinements of the genome structure were largely due to the chromosome conformation capture (3C) technique which allowed the rapid identification of chromatin regions residing in close proximity $[19,20]$. The basic principle of the $3 \mathrm{C}$ technique is that segments, which are spatially in close proximity within the cell nucleus, can be tethered together by cross-linking. After cross-linking and restriction enzyme digestion of the genome, the proximal segments remain covalently linked and segment ends can be, subsequently, ligated in dilute conditions. The ligation products can be analyzed using PCR-based methods [19]. A number of different 3C-type techniques have been developed to answer different biological questions including: 3C/3C-qPCR [19,21,22], 3C-seq/4C-seq [23,24], 4C (3C-on-a chip) [25-27], Chromatin Interaction Analysis by Paired-End Tag Sequencing (ChIA-PET) [28], 5C (3C carbon copy) [29], and $\mathrm{Hi}-\mathrm{C}$ [30]. All these techniques have their own advantages and limitations (Table 1) and have provided very valuable information on chromosomal interactions and gene transcription mechanisms [20,25,30,31]. 3C and $4 \mathrm{C}$ are quite work- and cost-intensive, given that they are only one-to-one fragment and one-to-all fragment techniques, respectively. Prior knowledge of the locus is necessary to define the region of interest.

Table 1 Comparison between different chromatin conformation capturing techniques (adopted and modified from [23])

\begin{tabular}{|c|c|c|c|}
\hline Method & Applications & Advantages & Limitations \\
\hline 3C-qPCR & One-to-one & Simple analysis & $\begin{array}{l}\text { Laborious, requires knowledge of the locus } \\
\text { and proper controls }\end{array}$ \\
\hline $3 C$-seq/4C-seq & One-to-all & $\begin{array}{l}\text { Good resolution, } \\
\text { good signal-to-noise ratio }\end{array}$ & $\begin{array}{l}\text { Restricted to single viewpoint per experiment } \\
\text { when multiplexing several viewpoints, analysis } \\
\text { requires extra bioinformatics expertise, not an } \\
\text { all-to-all genome-wide method }\end{array}$ \\
\hline 3C-on-chip (4C) & One-to-all & Relatively simple data analysis & $\begin{array}{l}\text { Poor signal-to-noise ratio, difficult to obtain } \\
\text { genome-wide coverage }\end{array}$ \\
\hline $5 C$ & Many-to-many & $\begin{array}{l}\text { Identifies interactions between } \\
\text { many individual fragments }\end{array}$ & $\begin{array}{l}\text { Very laborious, no genome-wide coverage, } \\
\text { primer design can be challenging. Analysis } \\
\text { requires advanced bioinformatics expertise }\end{array}$ \\
\hline $\mathrm{Hi}-\mathrm{C}$ & All-to-all & $\begin{array}{l}\text { Explores the genome-wide interactions } \\
\text { between all individual fragments }\end{array}$ & $\begin{array}{l}\text { Very expensive, requires a large sequence effort } \\
\text { to obtain sufficient coverage, approximately } 10 \text { to } \\
40 \mathrm{kbp} \text { resolution, requires advanced bioinformatics } \\
\text { expertise }\end{array}$ \\
\hline $\mathrm{T} 2 \mathrm{C}$ & Many-to-all & $\begin{array}{l}\text { Explores the interactome of a selected region } \\
\text { in cis but also in trans, high (restriction fragment) } \\
\text { resolution, cheaper than } \mathrm{Hi}-\mathrm{C} \text { and } 5 \mathrm{C} \text {, requiring only } \\
\text { half a lane of Illumina HiSeq2000 }\end{array}$ & $\begin{array}{l}\text { Is restricted to the selected regions of the } \\
\text { genome, } \\
\text { requires advanced bioinformatics expertise }\end{array}$ \\
\hline
\end{tabular}


The analysis of the interactions of several viewpoints with the aforementioned techniques in $3 \mathrm{C}$ and $4 \mathrm{C}$ is possible, but the choice for several viewpoints will increase the costs and work effort linearly. However, the number of viewpoints can also be limited due to the (often) limiting amount of available cell material. $5 \mathrm{C}$ is demanding in primer design and allows the analysis of interactions only among the primer designed fragments. Furthermore, genome-wide coverage is not possible. $\mathrm{Hi}-\mathrm{C}$ is very expensive as it requires extremely deep sequencing in order to cover the whole genome, even at a relatively low resolution of $40 \mathrm{kbp}$. The most recent $\mathrm{Hi}-\mathrm{C}$ data analysis has used a new algorithm and provided a genome-wide interaction map of $10 \mathrm{kbp}$ resolution. However, an enormous amount of sequencing is required (3.4 billion mapped paired-end reads from six biological replicates) [32]. Such effort is not affordable for most research groups and, in addition, the scientific interest is most of the time focused on a specific question involving a limited set of specific loci or domains. Hence, there is a need for a technique which eliminates most of the aforementioned limitations.

Here we present Targeted Chromatin Capture (T2C), a new 3C method, which does not involve a massive sequencing effort, but which results in a high resolution map of interactions for particular loci of interest. We used the well-studied human H19/IGF2 locus and compared the results of our new method with data from other chromatin conformation capturing techniques. Using the mouse $\beta$-globin locus we demonstrated that the method can reliably identify chromatin structural changes between different tissues and also allows the study of the role of individual transcription factors in the chromatin architecture.

\section{Overview of the procedure}

To overcome the aforementioned problems of the $5 \mathrm{C}$ and $\mathrm{Hi}-\mathrm{C}$ techniques we have developed the novel method T2C. The method has the advantage that it allows the analysis of the structure of the genome and all the interactions of selected regions of the genome at high resolution (single restriction fragments) without a massive sequencing effort and associated costs.

T2C employs a selective enrichment of the $3 \mathrm{C}$ ligation products in preselected regions of interest in order to identify their interactions within a domain as well as the compartmentalization of one or several specific regions of the genome. These regions can be continuous $\mathrm{Mb}$ sized genomic regions, but could also be a collection of smaller regions (a few kbp each). Every captured restriction fragment can be used as a single ' $4 \mathrm{C}$-seq viewpoint' and analyzed accordingly. The results of $\mathrm{T} 2 \mathrm{C}$ provide a local interaction map at a restriction fragment-level resolution accompanied with a lower sequencing effort and less intricate bioinformatics analysis than $\mathrm{Hi}-\mathrm{C}$. T2C also overcomes the limits of $5 \mathrm{C}$ since it identifies not only interactions within the targeted region(s), but also interactions between the targeted region(s) and with regions outside of them.

In brief, we have designed sets of unique oligonucleotide probes (ranging from 62 to 90 nucleotides) specific for all the restriction fragments and as close as possible to the end of the first restriction site $(M m$ - HindIII + NlaIII digest, $H s$ - BglII + NlaIII digest) in our regions of interest, the mouse $\beta$-globin locus and the human H19/IGF2 locus (see Methods). Alternative to continuous regions, separate genomic regions within one (or more) chromosomes could be analyzed simultaneously. The oligonucleotides are spotted on an array or can alternatively be captured on beads. Some fragment ends cannot be captured by a designed oligonucleotide due to the presence of repeat elements or the insufficient size of the restriction fragment end. Repetitive sequences are a general problem in all 3C-based methods, including $\mathrm{Hi}-\mathrm{C}$. The size limitation of the fragment end can be circumvented if necessary by a backup procedure with different enzymes (changing either the first or the second restriction enzyme or both), which generates a new set of end fragments or by mechanically shearing of the chromatin (instead of the second restriction enzyme digestion) which can result in fragment sizes of different length (see Discussion).

The first steps of the preparation of the chromatin conformation capturing library are carried out as in 3C-seq [23]. Basically, chromatin is cross-linked, followed by digestion with a 6 bp recognition restriction endonuclease, ligation in diluted conditions and decross-linking of the DNA. The library is subsequently digested with a frequently-cutting 4 bp recognition restriction endonuclease or mechanically sheared to obtain small fragments containing the ligation site, followed by end-repair and ligation of an adapter. Within the adapter, different barcodes can be included that would allow multiplexing of different samples. The resulting library is hybridized to the specific oligonucleotide probe set representing the area(s) of interest (either on an array or in a bead capturing procedure) to enrich specifically for the interacting fragments of the region of interest (all fragments positioned at the ends of the original $6 \mathrm{bp}$-cut fragments after the second $4 \mathrm{bp}$-cut and eliminate all fragments internal to the $6 \mathrm{bp}$ generated fragments). After extensive washing all ligation products including regions covered by the targeting-array are eluted and their sequence determined by Illumina-sequencing (Figure 1). The capture efficiency (the proportion of paired reads of total reads when at least one read of the paired end reads is located on a fragment represented by an oligonucleotide) is between $47 \%$ and $86 \%$ depending the cell type and the region (see Table 2). 


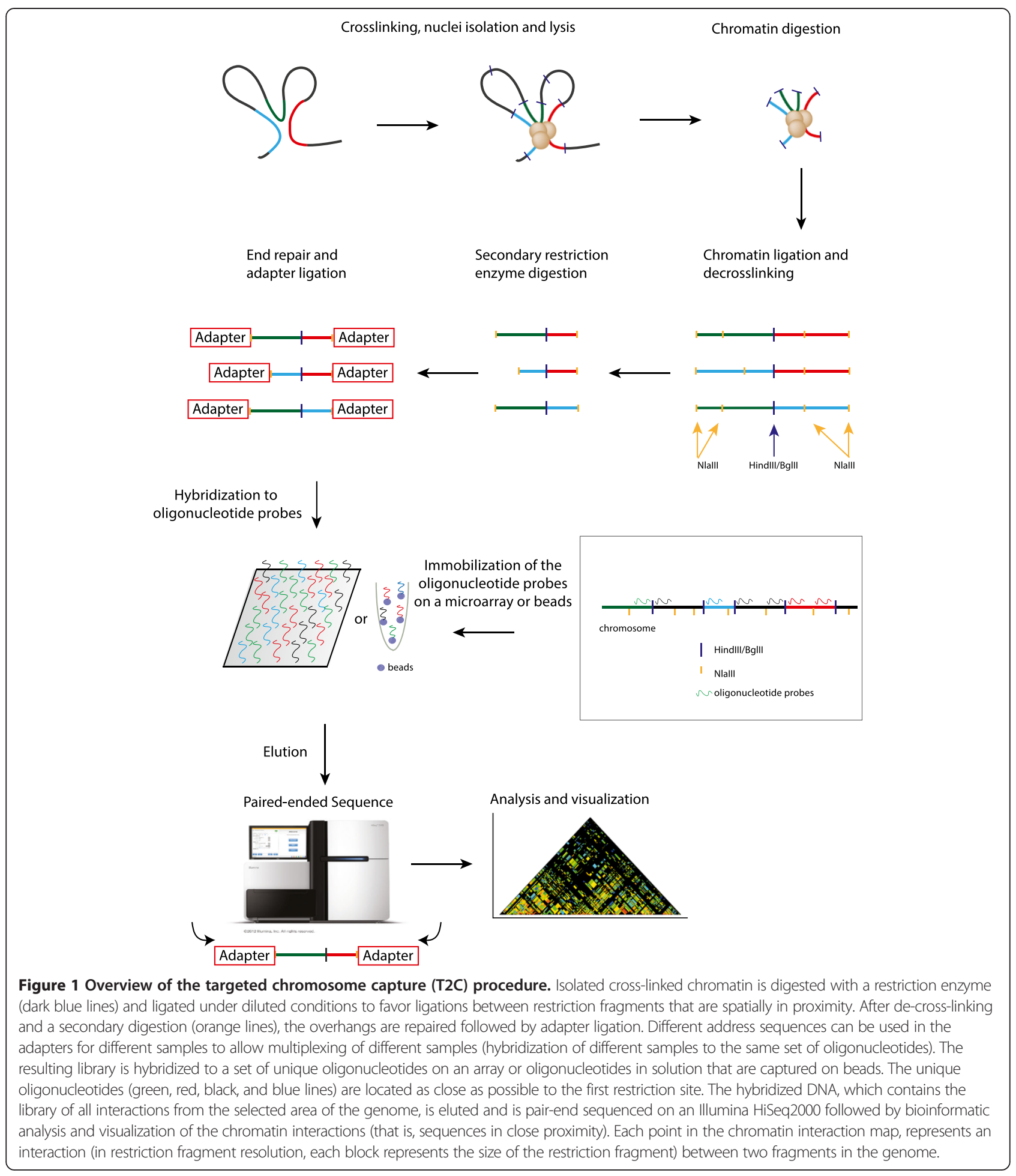

\section{Results}

\section{T2C identifies known long-range interactions}

We first have chosen the H19/IGF2 region on human chromosome 11 to test and compare the method to other 3C methods. Previously, we analyzed the 3D-structure of the locus by $3 \mathrm{C}$ to study the role of cohesin and CTCF for chromosomal long-range interactions [33] and also generated 4C-seq data [14] (Figure 2). Hi-C interaction maps were retrieved for IMR90 cells [1].

We selected unique oligonucleotides mapping near the ends of $344 \mathrm{BglII}$ generated fragments spanning 2.1 Mb around the H19/IGF2 locus (Table 2). This set of 525 
Table 2 Summary of information about the different experiments

\begin{tabular}{|c|c|c|c|c|c|c|c|c|c|c|c|c|}
\hline Type & $\begin{array}{l}\text { Genome } \\
\text { assembly } \\
\text { version }\end{array}$ & $\begin{array}{l}\text { Coordinates } \\
\text { oligo-nucleotide } \\
\text { positions }\end{array}$ & $\begin{array}{l}\text { Size of } \\
\text { area of } \\
\text { interest } \\
\text { (Mb) }\end{array}$ & $\begin{array}{l}\text { Median } \\
\text { resolution } \\
\text { (kbp) }\end{array}$ & $\begin{array}{l}\text { Raw } \\
\text { paired } \\
\text { reads }(n)\end{array}$ & $\begin{array}{l}\text { Paired reads } \\
\text { that could be } \\
\text { mapped to } \\
\text { the whole } \\
\text { genome }(n)\end{array}$ & $\begin{array}{l}\text { Mapped } \\
\text { paired } \\
\text { reads } \\
\text { between } \\
\text { the region } \\
\text { of interest } \\
\text { and the } \\
\text { whole } \\
\text { genome (n) }\end{array}$ & $\begin{array}{l}\text { Uniquely mapped } \\
\text { paired-reads in } \\
\text { the whole genome } \\
\text { without self-ligation } \\
\text { and and non- } \\
\text { digestion (n) }\end{array}$ & $\begin{array}{l}\text { Uniquely mapped } \\
\text { paired-reads } \\
\text { between the region } \\
\text { of interest and the } \\
\text { whole genome } \\
\text { without self-ligation } \\
\text { and non-digestion (n) }\end{array}$ & $\begin{array}{l}\text { Uniquely mapped } \\
\text { paired-reads inside } \\
\text { the region of } \\
\text { interest without } \\
\text { self-ligation and } \\
\text { non-digestion }(n)\end{array}$ & $\begin{array}{l}\text { 'Interactions' } \\
\text { inside the } \\
\text { region of } \\
\text { interest }(\mathrm{n})\end{array}$ & $\begin{array}{l}\text { Average number } \\
\text { of reads/interaction } \\
\text { in the region of } \\
\text { interest }(n)\end{array}$ \\
\hline $\begin{array}{l}\text { Mouse } \\
\text { fetal } \\
\text { liver }\end{array}$ & $\mathrm{mm} 9$ & $\begin{array}{l}\text { chr7: } 109876329- \\
111966581\end{array}$ & 2.1 & 2 & $65,165,916$ & $9,300,108$ & $5,716,401$ & $4,559,952$ & $2,723,515$ & 557,763 & 4,057 & 137 \\
\hline $\begin{array}{l}\text { Mouse } \\
\text { fetal } \\
\text { brain }\end{array}$ & mm9 & $\begin{array}{l}\text { chr7: } 109876329- \\
111966581\end{array}$ & 2.1 & 2 & $84,977,143$ & $6,380,256$ & $3,191,360$ & $3,018,169$ & $1,414,128$ & 271,177 & 2,369 & 114 \\
\hline HB2 & hg18 & $\begin{array}{l}\text { chr11: } 1100646 \text { - } \\
3173091\end{array}$ & 2.1 & 4.1 & $51,952,969$ & $13,813,662$ & $12,127,051$ & $5,503,770$ & $4,745,779$ & $1,929,245$ & 8,989 & 215 \\
\hline
\end{tabular}

Columns from left to right: Tissue type or cells; genome assembly version; summary of the positions of oligonucleotides (region of interest); the size and the median resolution of the area under investigation; the number of the raw paired-reads (before alignment, that is, all reads from the sequenator); the number of mapped paired reads that could be mapped back to the whole genome; the number of paired reads between the region of interest (fragments with oligonucleotides) and the whole genome; the number of uniquely mapped paired-reads in the whole genome after removal of the self-ligation and non-digestion events (See Methods); the number of uniquely mapped paired-reads between the region of interest (fragments with oligonucleotides) and the whole genome after removal of the self-ligation and non-digestion events; the number of uniquely mapped pairedreads inside the region of interest after removal of the self-ligation and non-digestion events; the number of 'interactions' between fragments in the region of interest; average number reads per interaction. The capture efficiency and purification (enrichment) by hybridization is high (that is, how many reads from the region of interest ('specific' reads) are found when compared to total reads, that is, the reads that are from other areas of the genome and not containing a sequence from the area of interest ('non-specific' reads). We find that the 'specific' reads represent $61 \%, 50 \%$, and $88 \%$ of total reads ('specific' plus 'non-specific') for mouse primary erythroid
genticis genome and not containing a sequence from the area of interest ('non-specific' reads)). We find that the 'specific' reads represent $61 \%, 50 \%$, and $88 \%$ of total reads ('specific' plus 'non-specific') for mouse primary erythroid
cells, mouse fetal brain cells, and HB2, respectively, including the self-ligation and non-digestion events. By removing those events those numbers change to $60 \%, 47 \%$, and $86 \%$, respectively. This means for example that $60 \%$ of the fetal liver reads $(2,723,515)$ represent $2.1 \times 10^{6}$ bases (the region of interest) while the remaining $40 \%$ of reads represents $3.10^{9}$ bases (the whole genome), numbers that indicate a high level of enrichment by the of the fetal liver reads $(2,723,515)$ represent $2.1 \times 10^{6}$ bases (the region of interest) while the remaining $40 \%$ of reads represents $3.10^{9}$ bases (the whole genome), numbers that indicate a high level of enrichment by the
hybridization step. 


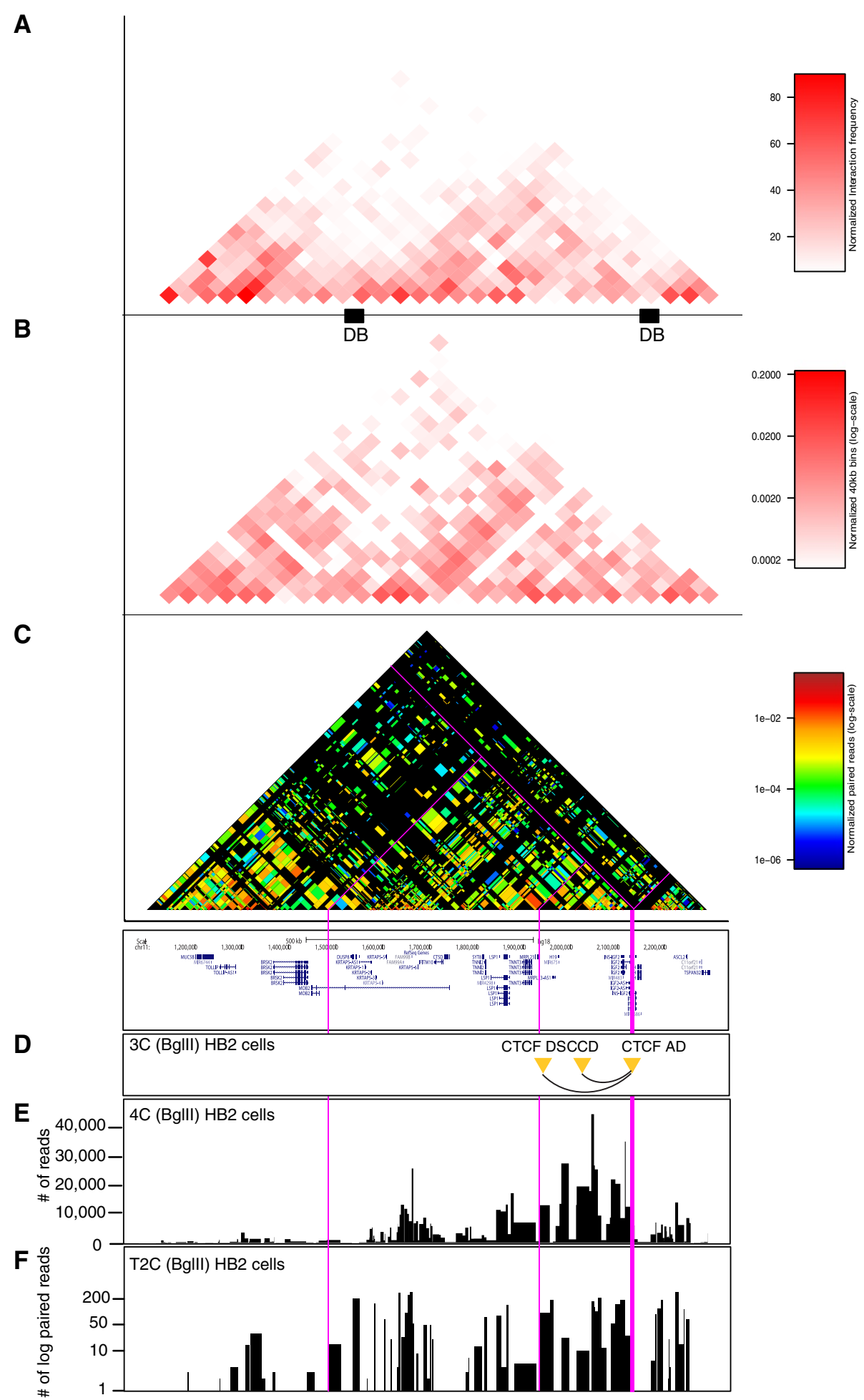

Figure 2 Comparison of interactions detected by $\mathrm{T} 2 \mathrm{C}$ for the human chr11p15.5 region with $\mathrm{Hi}-\mathrm{C}$ and $4 \mathrm{C}$-seq. (A) Hi-C data generated by Dixon et al. for IMR90 cells covering the H19//GF2 region of interest, presented at a resolution $40 \mathrm{kbp}$ with their respective domain boundaries (DB) depicted as black boxes [1]. (B) T2C interactions in HB2 cells at a $40 \mathrm{kbp}$ resolution. The overall topological domain pattern observed by the two methods is similar $\left(r_{s}=0.64, P<2.2 \times 10^{-16}\right)$. (C) T2C interaction with their actual resolution at restriction fragment level. (D) Interactions detected by $3 C$ [33]. The restriction fragments are indicated with yellow triangles. (E) 4C-seq interaction data [14], for a viewpoint close to the IGF2 gene. (F) Interactions observed for a particular viewpoint by T2C plotted with logarithmic $y$-axis. The position of the viewpoint is indicated as bold pink line to allow a direct comparison between the methods. The thin pink lines indicate a couple of interaction fragments for ease of comparison. 
oligonucleotides was spotted on a capture array. A ligation fragment library was generated from the breast endothelial cell line 1-7HB2 (abbreviated HB2) after digestion with BglII and NlaIII according to the 3C-seq protocol [23] (see also Figure 1). The library was subsequently hybridized to the capture array. After elution from the capture array the captured DNA fragments were amplified by a PCR with low cycle number (12 cycles) and sequenced by paired-end Illumina sequencing (see Methods).

To demonstrate that $\mathrm{T} 2 \mathrm{C}$ reveals a similar overall interaction pattern and compartmentalization of the locus as observed by Hi-C in IMR90 cells [1] we first binned the paired-reads into $40 \mathrm{kbp}$ bins (Figure 2A, B). The interaction patterns at this level of resolution show that the topological domain is maintained between different cell types, HB2 [14] versus IRM90 [1] with a Spearman's rank correlation coefficient $r_{s}=0.64\left(P<2.2 \times 10^{-16}\right)$.

However, with $\mathrm{T} 2 \mathrm{C}$ we obtained a chromatin interaction map at restriction fragment resolution (Figure $2 \mathrm{C}$, each block represents one restriction fragment), revealing significantly more detail with respect to the general chromatin organization of the region when visualized by a logarithmic and rainbow-like colored interaction frequency. To first validate $\mathrm{T} 2 \mathrm{C}$ in comparison to $3 \mathrm{C}$ and $4 \mathrm{C}$-seq we compared the interactions of a single restriction fragment (CTCF AD viewpoint) [33] to interactions detected for this fragment by $3 \mathrm{C}$ [33] and 4C-seq [14] (Figure 2D, E, F). Although there are some variations in the read coverage of the individual interactions, similar interactions can be observed by both $4 \mathrm{C}$-seq and T2C. Moreover, both methods detect interactions which we previously observed with $3 \mathrm{C}$ [33]. It should be noted that an important difference between $4 \mathrm{C}$-seq and $\mathrm{T} 2 \mathrm{C}$ is the number of PCR amplification cycles. For T2C this is on average 12 cycles (only after capture) whereas for $4 \mathrm{C}$-seq it is 30 cycles. The lower number of cycles will give less PCR bias of the different fragments relative to each other, because fragments have different PCR efficiencies.

We conclude that the T2C method yields interaction data at a resolution identical to $4 \mathrm{C}$-seq for the individual restriction fragments (median approximately $4 \mathrm{kbp}$ resolution) and that when $\mathrm{T} 2 \mathrm{C}$ is performed for a continuous region over $2 \mathrm{Mb}$ it can reproduce the overall topological domain structure that was observed by $\mathrm{Hi}-\mathrm{C}$.

\section{T2C identifies different interaction networks based on different biological materials}

Next we used the extensively characterized mouse $\beta$-globin locus as a model system to show that the T2C method can detect reliably conformational changes due to activation of the genes in vivo at high resolution (Figures 3 and 4). We further showed, with an intersection between ChIP-seq derived chromatin protein data and $\mathrm{T} 2 \mathrm{C}$, that chromatin proteins may be involved in forming or maintaining the $3 \mathrm{D}$ structure of the genome (Figure 5).

The mouse $\beta$-globin locus undergoes structural changes upon activation in erythroid tissue $[20,34,35]$, but is surrounded by silent olfactory receptor genes, which are only expressed in the olfactory epithelium. The major difference between the H19/IGF2 locus and the $\beta$-globin locus is that the $\beta$-globin locus is embedded in a large area of inactive genes. Thus two patterns of interactions may be expected in erythroid cells, those important for the globin locus and those present in inactive chromatin. We selected a region of $2.1 \mathrm{Mb}$ around the locus (Table 2) containing 719 restriction fragments of the restriction enzyme HindIII (6 bp recognition site). About 800 oligonucleotide probes were designed close to the ends of the fragments. To analyze the locus in its active state we used primary erythroid cells from fetal liver which were compared to fetal brain cells as a model of inactive loci. Based on results from previous $3 \mathrm{C}$ studies of the locus $[20,35]$ we expected in primary erythroid cells a higher number of interactions around the $\beta$-globin gene and between the $\beta$-globin gene and its regulatory elements.

The analysis of the hybridized fragments shows that almost the entire $2.1 \mathrm{Mb}$ appears to be part of one topological domain (with two possible subdomains, one of which contains the $\beta$-globin locus) with the next domain starting near the end of the selected sequences (due to the repetitive sequences and the borders of the region of interest, that topological domain cannot be depicted clearly, in agreement with Dixon et al. [1]) both in mouse primary erythroid cells (Figure 3A, right hand side) and mouse fetal brain cells (Figure $3 \mathrm{~B}$ ) with many interactions within the topological domain (Figure $3 \mathrm{C}$ and 3D). Although the topological domain structure between the different biological materials is similar, there appear to be fewer interactions in mouse fetal brain cells relative to mouse primary erythroid cells due to the inactivity of the locus in the brain (Figure 3). Focusing on the $\beta$-globin region, all the well-known interactions in the $\beta$-globin locus are detected in the primary erythroid cells. The known interactions, such as between the $\beta$-globin promoter and Locus Control Region (LCR) (Figure 4B, adapted and modified from Drissen et al., with blue line depicting the interactions for primary erythroid cells and with grey the interactions for mouse fetal brain cells) and between the LCR-3'HS1 are clearly visualized [16,20,35] (Figure 4A). These interactions are absent from the fetal brain sample (Figure $4 \mathrm{C}$ ). Furthermore, the main regulatory region (HS1-6) shows the well-known interaction with the $\beta$-globin genes and HS1 at the 3 'end of the locus in fetal liver cells but not in brain $[16,20]$. In addition, for the $\beta$-globin promoter we identify a few additional interactions further away than the ones previously reported. These are located even 


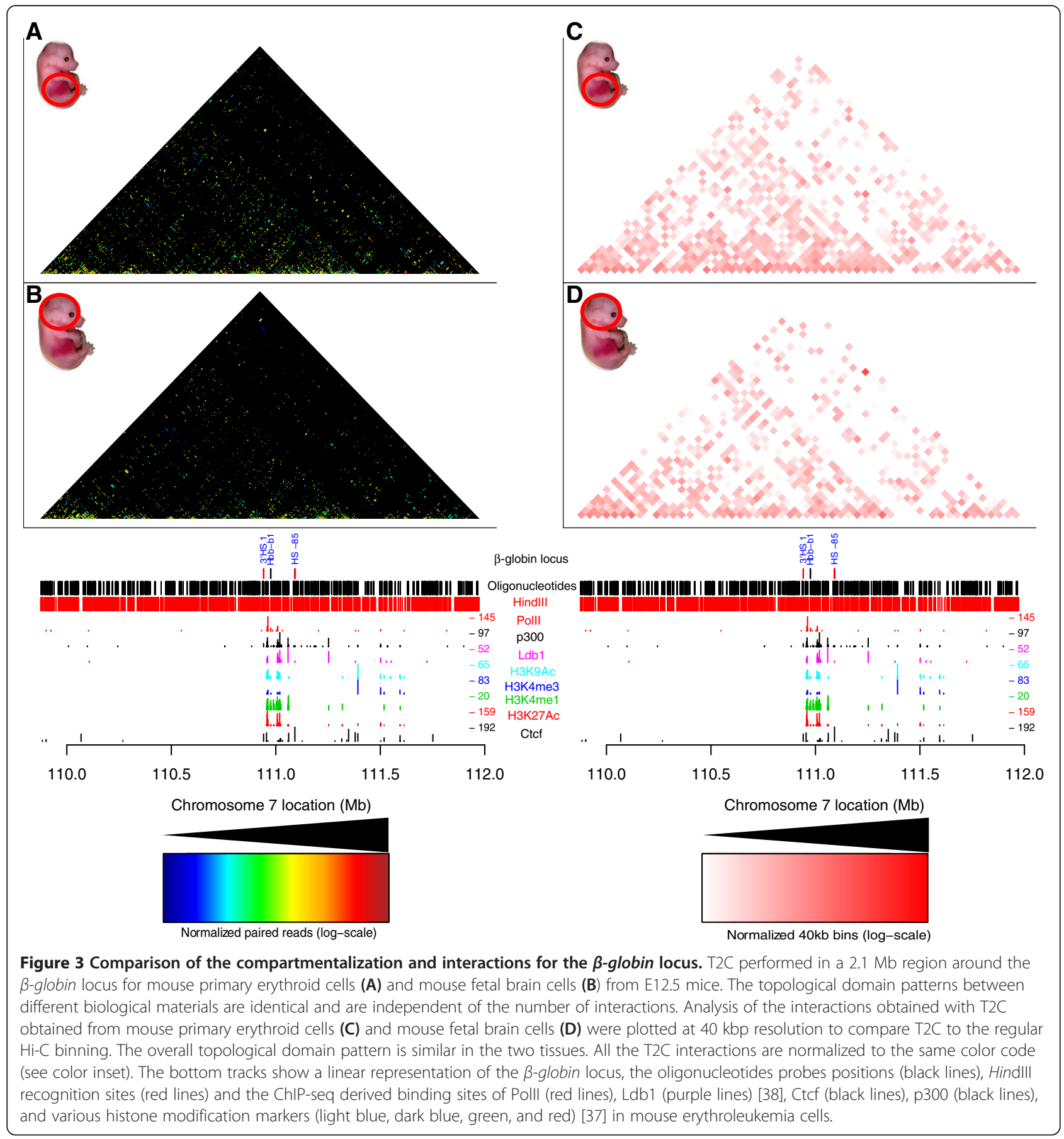

approximately $1 \mathrm{Mb}$ far from the $\beta$-globin promoter (Figure 3A). It is unknown whether these interactions are related to the functioning of the $\beta$-globin genes or whether these DNA elements are in close proximity due to the folding of the domain, although their absence in the fetal brain suggests they have a role in the regulation of the globin $\beta$-globin. In addition to the interactions in cis, the $\beta$-globin $(H b b-b 1)$ gene and the LCR also contact a number of positions on other chromosomes.
T2C in combination with ChIP-seq identifies factor specific interactions

We also compared the interactions of the binding sites of an important regulatory transcription factor in mouse primary erythroid cells, the Ldb1 complex, and the insulator binding protein Ctcf (Figure 5A-D). Ldb1 is highly enriched on the $\beta$-globin locus and its LCR in mouse primary erythroid cells compared to fetal brain cells [36]. By visualizing only the restriction fragments containing the 


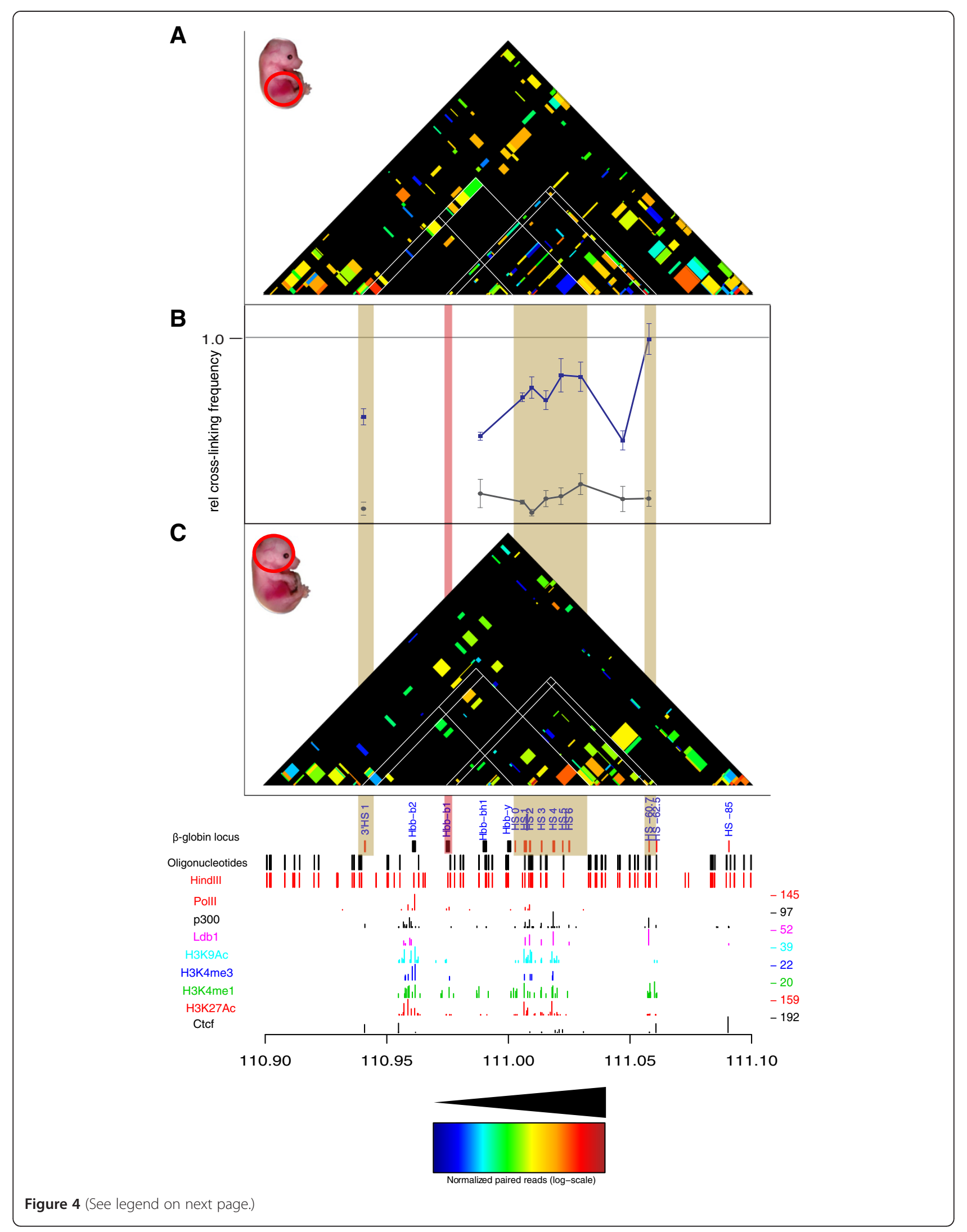


(See figure on previous page.)

Figure 4 Comparison of T2C with $3 \mathrm{C}$-qPCR for the $\boldsymbol{\beta}$-globin promoter. T2C for mouse primary erythroid cells (A) and mouse fetal brain cells (C) from E12.5 mice, revealed the same interactions from the $\beta$-globin promoter when comparing them to 3C-qPCR (B). The 3C-qPCR was adapted and modified from Drissen et al. [16] with blue line depicting the interactions for primary erythroid cells and with grey the interactions for mouse fetal brain cells from E12.5 mice. White lines indicate the areas of particular interest (such as 3'HS1, $\beta$-globin promoter, Locus Control Region (LCR) and 5' HS-60/-62) in the $\beta$-globin locus. Interactions between LCR, the $\beta$-globin promoter and the 3'HS1 are lost in mouse brain cells. The shaded vertical bars indicate the comparison between the different panels. The red vertical bar indicates the $\beta$-globin promoter. All the T2C interactions are normalized to the same color code (see color inset). The bottom tracks show a linear representation of the $\beta$-globin locus, the oligonucleotides probes positions (black lines), HindIII recognition sites (red lines) and the ChIP-seq derived binding sites of PollI (red lines), Ldb1 (purple lines) [38], Ctcf (black lines), p300 (black lines), and various histone modification markers (light blue, dark blue, green, and red) [37] in mouse erythroleukemia cells.

Ldb1 or Ctcf binding sites as determined by ChIP-seq in fetal liver derived mouse erythroleukemia cells (MEL) $[37,38]$, we can immediately deduce in which interactions the Ldb1 complex (Figure 5E, F) or Ctcf (Figure 5G, H) are involved. In addition, we can identify the restriction fragments that represent gene promoter fragments (by Histone 3 Lysine 4 trimethylation (H3K4me3)) or enhancer fragments (marked by H3K4me1, that is, in the LCR, HS-60, and -62.5) or neither of these, by plotting the histone modifications ChIP-seq profiles [37]. Interestingly the 3' $\mathrm{HS} 1$ and HS-85 belong to the latter class and have robust Ctcf but not Ldb1 binding sites. This suggests that they are 'structural' elements which would fit with the observation that the deletion of the 3'HS1 results in a loss of looping but not in a decrease of $\beta$-globin mRNA levels [13]. In contrast the enhancer immediately $3^{\prime}$ of the $\beta$-globin enhancer is apparent, but it does not appear to interact with any distal elements. It is also clear that in mouse primary erythroid cells Ldb1 (Figure 6A) and Ctcf (Figure 6B) occupy restriction fragments that have more interactions with other positions in the locus when compared to mouse brain cells. In addition the median distance on the linear chromosome between two fragments in spatial proximity is larger in primary erythroid cells for both Ldb1 (Figure 6C) and Ctcf (Figure 6D) binding sites. This suggests that this area of the genome is less condensed. We conclude from these experiments that T2C indeed detects topological domains and the different interactions between and within domains. These interactions depend on the expression status of the genes such as the active $\beta$-globin locus in primary erythroid cells versus the same silent locus in fetal brain. In addition, the high level of resolution of the interactions allows novel observations such as shown for the $\beta$-globin locus Ldb1 and Ctcf binding sites and immediately shows which of these binding sites interact with each other and where they are positioned on the linear genome.

\section{Discussion}

The importance of the role of chromatin interactions in the regulation of the gene transcription is well established [9,39-42]. However, there is still an increasing need for a quick, easy, and affordable technique to provide the information on chromatin interactions and the compartmentalization of the genome. T2C is affordable to most scientific groups and will meet in a satisfactory manner their needs for detecting high resolution chromatin organization of selected loci. Every restriction fragment can serve as a 'viewpoint' and all their interactions, either short or long or to other chromosomes (data not shown), can be identified. Thus multiple $3 \mathrm{C}$-seq, $4 \mathrm{C}$ seq or $5 \mathrm{C}$ experiments do not have to be performed. Moreover, with $\mathrm{T} 2 \mathrm{C}$ the compartmentalization of the genome can be identified in the regions of interest without requiring the large sequencing effort of $\mathrm{Hi}-\mathrm{C}$, which would increase the costs tremendously. Furthermore, due to the $\mathrm{T} 2 \mathrm{C}$ design, a better coverage and resolution of the locus is obtained when compared to other genome wide techniques (like $\mathrm{Hi}-\mathrm{C}$ and $3 \mathrm{C}$ with its derivatives) using a 6 bp cutter as first restriction enzyme. Here we multiplexed two samples, but by multiplexing more than two samples the costs are likely to be reduced significantly without sacrificing the quality of the output. We have recently successfully used 13 samples per sequencing lane, including the $\beta$-globin locus which showed the same interactions (data not shown).

The resolution of $\mathrm{T} 2 \mathrm{C}$ is based on the restriction enzyme used. Digesting cross-linked chromatin from primary erythroid cells and HB2 cells with HindIII or BglII, resulted in a median resolution of $2 \mathrm{kbp}$ and $4.1 \mathrm{kbp}$, respectively (Table 2). That provides a significantly better resolution than the usual $40 \mathrm{kbp}$ bins obtained with $\mathrm{Hi}-\mathrm{C}$. Furthermore, comparing T2C with 4C-seq [14] and Hi-C [1] for the H19/IGF2 locus (Figure 2) and with already published 3C-qPCR data for the $\beta$-globin locus $[16,20,35]$, the same topological domains and chromatin interaction networks were identified. Taken together, all these results reveal the strengths of the $\mathrm{T} 2 \mathrm{C}$ as a tool to identify all the interactions and the compartmentalization of specific regions of the genome.

In addition, the $\mathrm{T} 2 \mathrm{C}$ interactions are easily connected to the factors that play a role in these interactions or the type of elements (promoters/enhancers) involved in the interactions. Ldb1 and Ctcf are important proteins which mediate chromatin interactions. Ldb1 is an important transcription factor necessary for primitive mouse 


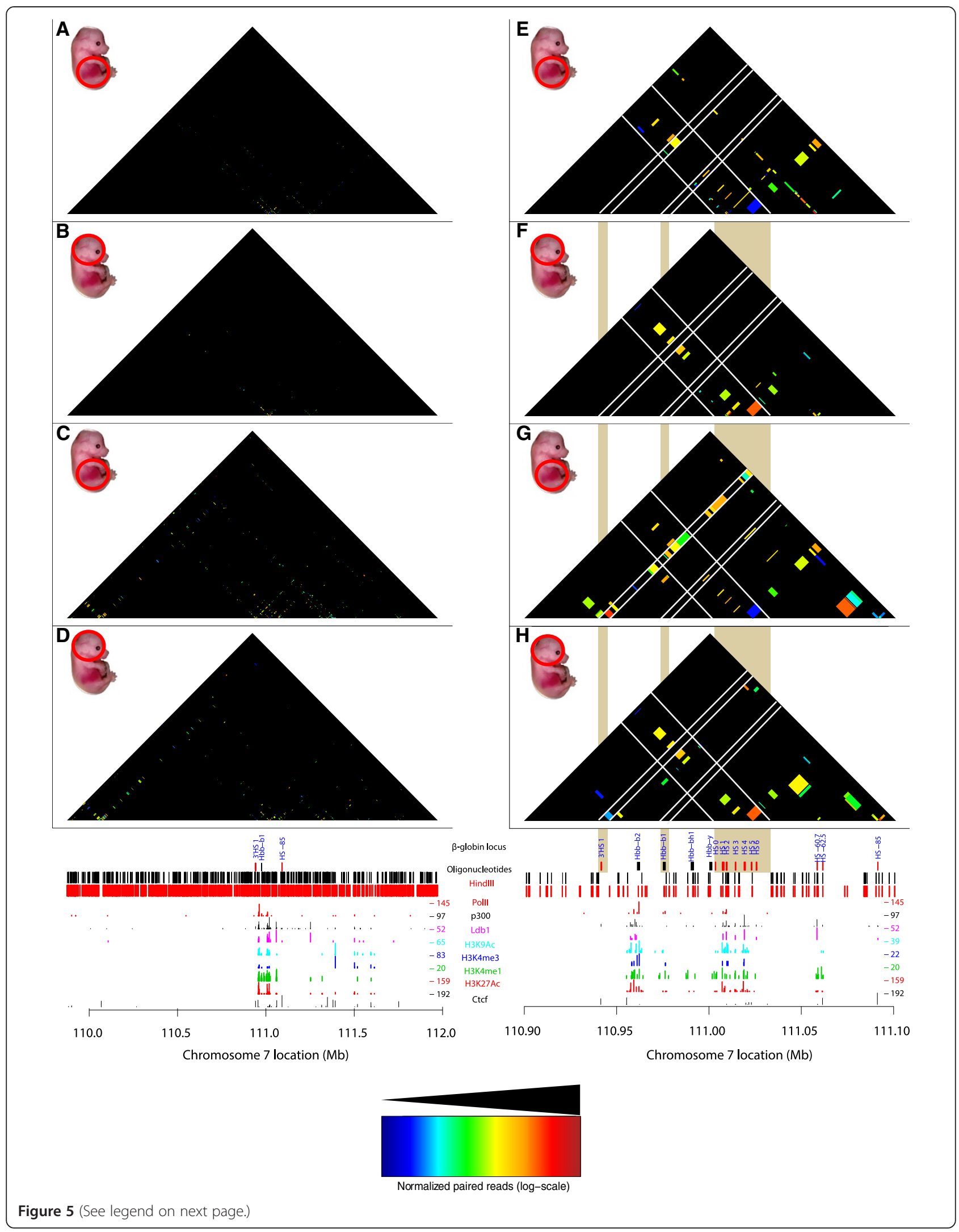


(See figure on previous page.)

Figure $\mathbf{5}$ T2C/ChIP-seq intersection plot. A comparison of the interactions containing one or two fragments with a Ldb1 or Ctcf binding site. Interactions are plotted, at restriction fragment resolution, over a $2.1 \mathrm{Mb}$ region around the $\beta$-globin locus for $L d b 1$ (A, B) or Ctcf (C, D) for mouse primary erythroid cells $(\mathbf{A}, \mathbf{C})$ and mouse fetal brain cells $(\mathbf{B}, \mathbf{D})$ from E12.5 mice. The topological sub-domain around the $\beta$-globin locus is clearly depicted in the mouse primary erythroid cells when compared to mouse brain cells. Focusing on the $\beta$-globin locus, T2C-intersection plots, at restriction fragment resolution, of interactions that contain a Ldb1 bound fragment $(\mathbf{E}, \mathbf{F})$ or a Ctcf bound fragment $(\mathbf{G}, \mathbf{H})$, for mouse primary erythroid cells $(\mathbf{E}, \mathbf{G})$ and mouse brain cells $(\mathbf{F}, \mathbf{H})$. White lines indicate particular areas of interest (like $3^{\prime} H S$ 1, the $\beta$-globin promoter and the Locus Control Region (LCR)) in the $\beta$-globin locus. The mouse primary erythroid cells interactions between LCR, $\beta$-globin promoter, and $3^{\prime} \mathrm{HS} 1$ are lost in mouse brain cells. The shaded vertical bars indicate the comparison between the different panels. All the interactions are normalized to the same color code (see color inset). The bottom tracks show a linear representation of the $\beta$-globin locus, the oligonucleotides probes positions (black lines), HindllI recognition sites (red lines) and the ChIP-seq derived binding sites of Polll (red lines), Ldb1 (purple lines) [38], Ctcf (black lines), p300 (black lines), and various histone modification markers (light blue, dark blue, green, and red) [37] in mouse erythroleukemia cells.

hematopoiesis and for the development of megakaryocytes $[43,44]$ and controls essential hematopoietic pathways in mouse early development [45]. Depletion of Ldb1 is lethal for mouse embryos after E9.5 with severe effects such as impairment of hematopoietic and vascular development [46]. It is well established that the LCR has higher interaction frequencies with the $\beta$-globin locus in mouse primary erythroid cells comparing to mouse brain cells
$[16,20,35]$ and that Ldb1 is significantly enriched in the LCR region in mouse primary erythroid cells relative to mouse fetal brain cells [36] (Figure 5E vs. Figure 5F). Furthermore, Ctcf is an insulator binding protein known to be involved in chromatin conformation [33] and is enriched at the boundaries of topological domains [1]. Ctcf mediates long range interactions in the $\beta$-globin locus [13] (Figure 5C vs. Figure 5D and Figure 5G vs. Figure 5H).
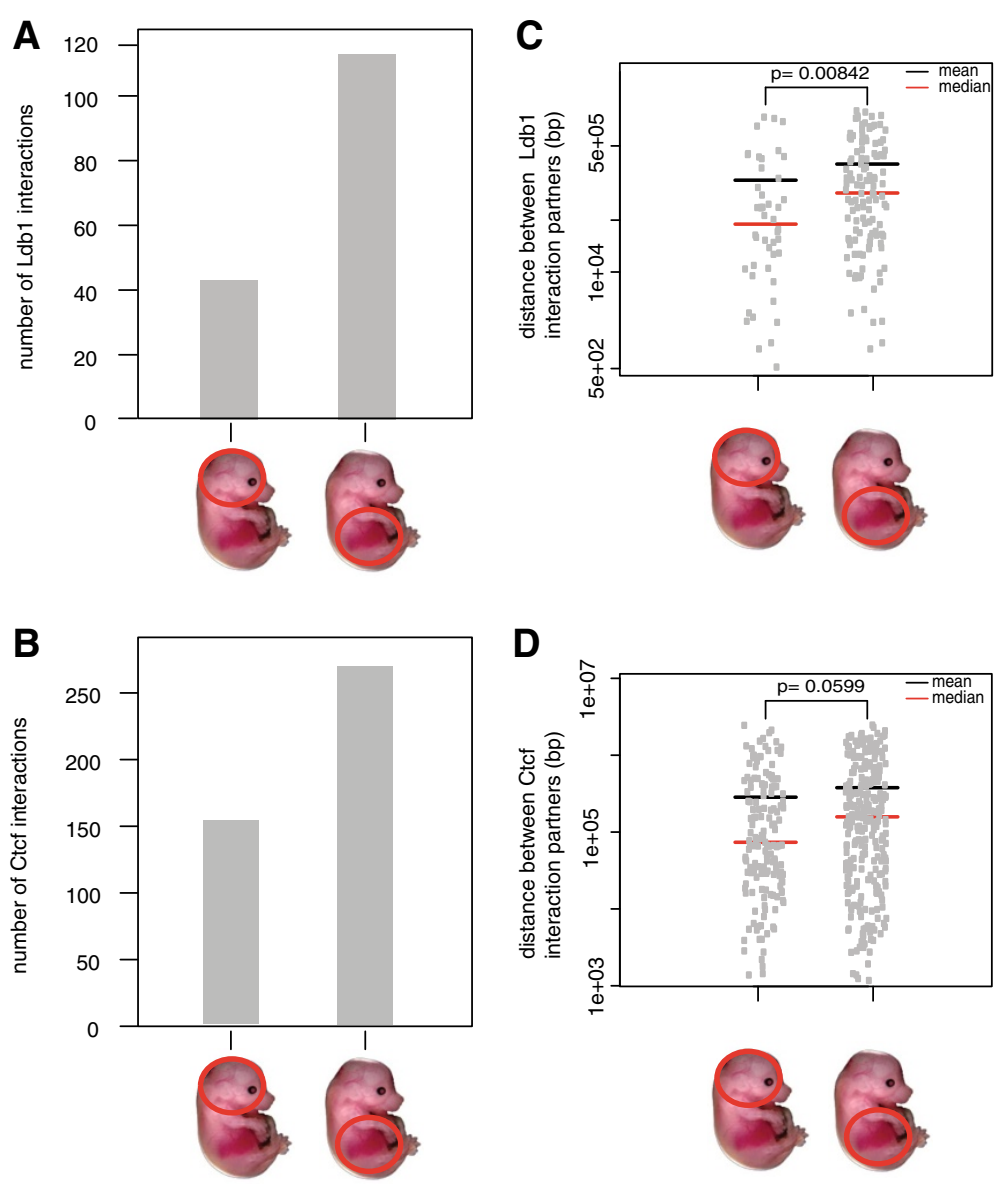

Figure 6 The mean, median, and the number of T2C interactions for the Ldb1 or Ctcf containing fragments. The number of Ldb1 (A) and Ctcf (B) interactions is lower in mouse fetal brain when compared to primary erythroid cells. Furthermore, the mean and the median of the distance between either $\mathrm{Ldb} 1$ (C) or Ctcf (D) interaction partners is lower in mouse fetal brain cells when compared to mouse primary erythroid cells. $P$ values were calculated using the Mann-Whitney $U$ test. 
Hence, it is no surprise that for Ldb1 and Ctcf occupied restriction fragments we observe a higher number of interacting fragments at larger linear distances of fragments that interact in mouse primary erythroid cells than in mouse brain cells (Figure 6). This effect can be explained by the fact that the $\beta$-globin locus is active in mouse primary erythroid cells. Furthermore, we observe that the boundaries of the topological domain, which contains the $\beta$-globin locus, are easily observed in mouse erythroid cells (Figure 3A). That is prominent when depicting only the Ctcf interacting fragments (Figure 5C vs. Figure 5D). Furthermore, the number of interactions within that topological domain, appear higher in the erythroid cells comparing to fetal brain cells (Figure 3A vs. Figure 3B, Figure $6 \mathrm{~A}, \mathrm{~B})$. We hypothesize that this is due to the fact that the $\beta$-globin locus is active with open chromatin in mouse primary erythroid cells. Hence, the chromatin has a different conformation by enabling the interaction between many different elements necessary for the regulation of the gene [34]. However, in mouse fetal brain cells, where $\beta$-globin locus is not active, that is not necessary and there are no important elements that need to spatially be in close proximity.

The method may be improved by bringing the cost further down. For example each of the $\beta$-globin locus experiments was carried out by using one sequencing lane on an Illumina HiSeq machine for each different biological sample (mouse primary erythoid cells and mouse fetal brain cells). That yielded after comprehensive data analysis and 271,177 and 557,763 paired-reads within the limits of the region of interest excluding self-ligations and uncut fragments for both fetal brain and liver (see Methods). These reads represented 2,369 and 4,057 distinct interactions with 114 and 137 reads per interaction on average for fetal brain and liver, respectively (Table 2). The read frequency of the highest $20 \%$ of the interactions is from 11,858 to 202 in fetal liver and from 29,637 to 188 (the top $30 \%$ is from 11,858 to 123 and 29,637 to 120 for fetal liver and fetal brain, respectively). The bottom $20 \%$ account for four reads in both tissues (while 30\% account for nine and 13 for fetal liver and fetal brain, respectively). The question then becomes whether one could do more samples per lane (that is, a reduction in cost per sample) which would result in fewer reads per interaction point. The decision on this depends to some extent on the research question asked. Analysis of functional interactions and/or the 'rough' overall structure of a locus, can be achieved by using a range between $1 / 2$ and $1 / 13$ of a sequencing lane which will dramatically lower the costs without losing much information.

We also considered using mechanical shearing instead of a secondary restriction enzyme. The advantage of the secondary restriction enzyme over mechanically shearing is that it is very reproducible and provides a better repair step of the ends and hence ligation of the adapters. The possible disadvantage of the second cleavage would seem to be a loss of fragment, because a number of fragments would be represented by one or no oligonucleotide. However when the oligonucleotides are used in excess, as in $\mathrm{T} 2 \mathrm{C}$, there is virtually no statistically significant difference in detecting the reads of fragments represented by two, one, or no oligonucleotides (Figure 7). Mechanically shearing would have the advantage that the chance of capturing a fragment is improved, because some of the secondary restriction sites are too close to the primary restriction sites. However the disadvantages are that mechanically shearing is random, which will have the same possible loss addressed above, but more importantly mechanical shearing is difficult to standardize between different laboratories. Using two different sets of oligonucleotides in combination with two different restriction enzymes for the first or second cleavage would give the most advantage because fewer fragments would be lost and the overall resolution and coverage would be further improved.

The 'quantification' could be further improved by spiking the samples with control cells preferably from another species, to allow easy recognition of the spike when mapping the sequences back to the genome during the analysis of the ligated fragments. This would also require the addition of a spike specific set of capturing oligonucleotides. Spiking the sample with a DNA sample with a different address sequence at the amplification and sequencing stage of the procedure would also be an improvement, although it would be less quantitative than the spiking with cells at the start of the procedure. The normalization of the signals using the capture efficiency of each of the fragments (Figure 7) also increases the 'quantification', although it should be noted these are all relative numbers rather than a real quantification because a number of parameters cannot be controlled or assessed properly.

Because $\mathrm{T} 2 \mathrm{C}$ is focused on particular regions of interest, it would be easy to design a set of oligonucleotides for a number of loci that are known to be associated with a particular disease and design a diagnostic kit on that basis that could handle many samples at the same time. Since SNPs are often linked to diseases, dedicated oligonucleotides for them can be designed in order to assess their effect in long range interactions and the regulation of the gene transcription. For non-clinical research purposes the size of the region used in our experiments is sufficient (more than $2 \mathrm{Mb}$ ) to extract safe conclusions about the local chromatin interactome and the compartmentalization of the genome.

\section{Conclusions}

We conclude that T2C can be used as an affordable, costeffective, diagnostic tool with single restriction fragment 


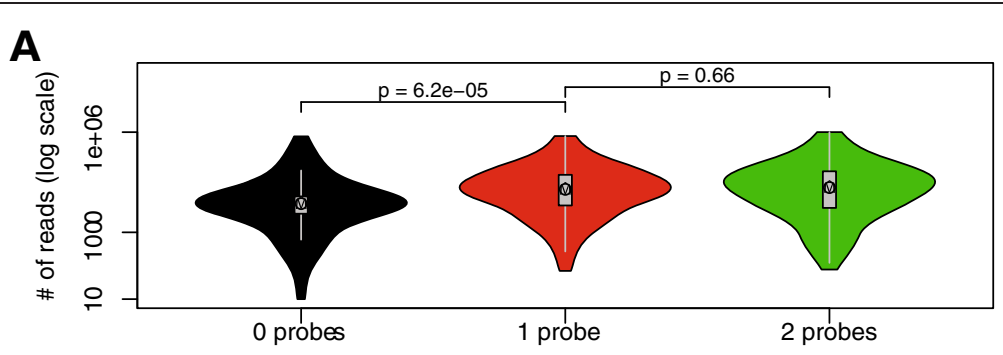

B

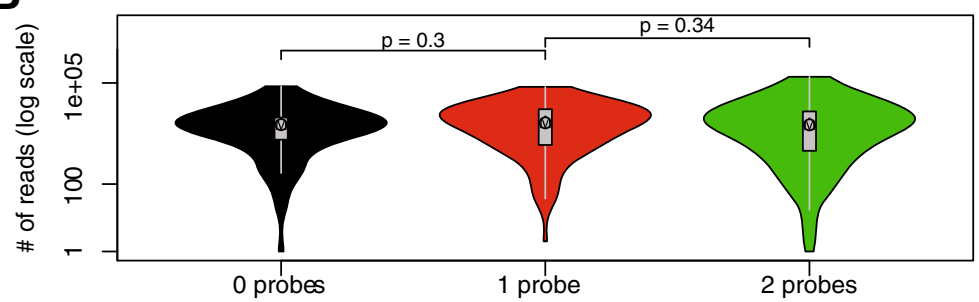

Figure 7 Comparison of capture efficiencies. The efficiency with which each fragment of the selected area is captured was derived from counting all of the reads for any particular fragment, that is, all its interactions, its self-ligation, and non-cleaved material and plotting these against the presence of two, one, or no oligonucleotides (probes) in the fragment (A). This shows that the presence of one or two oligonucleotides does not make a difference in the capture as would be expected under conditions where the oligonucleotides are in saturation. When no oligonucleotides are present for a particular fragment, the number of reads will be lower, because the reads due to self-ligation cannot be captured. When the reads are corrected for the self-ligation and non-cleaved fragments this difference largely disappears (B). $P$ values were calculated using the Mann-Whitney $U$ test.

resolution to explore the local spatial organization of the genome and chromatin interactions without requiring laborious procedures or massive sequencing efforts.

\section{Methods}

\section{Oligonucleotide design}

A microarray for the $\beta$-globin locus was designed containing unique oligonucleotides and physically as close as possible to the HindIII restriction sites spanning 2.1 Mb around the gene (chr7: 109876329-111966581, mm9). For the H19/IGF2 locus unique oligonucleotides were designed close to BglII restriction sites (chr11:1100646-3173091, hg18) spanning an area of 2.1 Mb (Table 2).

The oligonucleotides were designed with the following criteria, they should be: (1) as close as possible to the first restriction site; (2) a unique DNA sequence within the area of interest and preferably in the entire genome; (3) similar melting temperatures, but with different base composition and the length; (4) oligonucleotides which exceed the second restriction site due to very small end fragments, were trimmed keeping in mind to stay close to the same melting temperature.

A custom-made NimbleGen Sequence Capture 2.1 M capture array is produced separately for the H19/IGF2 locus and for the $\beta$-globin locus containing for each one the oligonucleotides which satisfy the aforementioned criteria. The oligonucleotides, 525 for the H19/IGF2 locus and 800 for the $\beta$-globin locus, were replicated proportionally and equally up to $2.1 \mathrm{M}$ in total for each design, that is, for the $\beta$-globin locus each of the 800 oligonucleotides was spotted in 2,625 spots.

\section{Chromatin isolation and library preparation}

Nuclei from approximately $10^{7}$ mouse primary erythroid cells from mouse fetal liver E12.5, mouse fetal brain cells E12.5, and a human breast endothelial cell line (HB2) were isolated, cross-linked (in $2 \%$ formaldehyde at room temperature) quenched with $1 \mathrm{M}$ glycine and were resuspended in lysis buffer (10 mM Tris- $\mathrm{HCl}$ ( $\mathrm{pH} 8.0$ ), $10 \mathrm{mM} \mathrm{NaCl}, 0.2 \%$ (vol/vol) NP-40 and $1 \times$ protease inhibitor solution). The chromatin was digested with a 6-cutter (400 units of HindIII for mouse cells and BglII for the HB2 cells) and ligated using 100 units of T4 DNA ligase (Promega) under conditions favoring intramolecular ligation events. After reversing the cross-link at $65^{\circ} \mathrm{C}$ overnight, $50 \mu \mathrm{g}$ of the resulting DNA chromatin library were digested with a frequent 4-cutter (DpnII or NlaIII for the mouse cells, NlaIII for the HB2 cells, at a DNA concentration of $100 \mathrm{ng} / \mu \mathrm{L}$, using 1 unit of enzyme per $\mu \mathrm{g}$ of DNA). All these steps were performed according to the initial steps of 3C-seq protocol, as described previously [23].

The final library is prepared for analysis on the Illumina Cluster Station and HiSeq 2000 Sequencer according to the Illumina TruSeq DNA protocol with modifications (www.illumina.com). In short, the digested library is purified using AMPure XP beads (Beckman Coulter), endrepaired, and cleaned using AMPure XP beads. The now blunt-ended fragments were A-tailed using the Klenow exo enzyme in the presence of ATP and purified again 
using AMPure XP beads. Then indexed adapters provided by Illumina were ligated to the A-tailed DNA fragments with subsequent purification using AMPure XP beads.

\section{Array capturing}

The resulting adapter-modified DNA library (300 to $500 \mathrm{ng}$ ) was hybridized in $35 \mu \mathrm{L}$ for $64 \mathrm{~h}$ at $42^{\circ} \mathrm{C}$ on a custom-made NimbleGen Sequence Capture 2.1 M capture array according to NimbleGen Sequence Capture array protocol (www.nimblegen.com/seqcapez) on the NimbleGen Hybridization System. The captured DNA fragments are eluted from the capture array and purified using MinElute columns (Qiagen). The yield for a positive region (a fragment inside the region of interest) and a negative region (a fragment outside the region of interest) differ by $>30$-fold on average. The captured DNA fragments are amplified by 12 PCR cycles. PCR products are purified using AMPure XP beads and eluted in $30 \mu \mathrm{L}$ of re-suspension buffer. One microliter is loaded on an Agilent Technologies 2100 Bioanalyzer using a DNA 1000 assay to determine the library concentration and to check for quality.

\section{Cluster generation and high throughput sequencing}

Cluster generation is performed according to the Illumina Cluster Reagents preparation protocol (www.illumina. com). Briefly, $1 \mu \mathrm{L}$ of a $10 \mathrm{nM}$ TruSeq DNA library stock DNA is denatured with $\mathrm{NaOH}$, diluted to 9-10 pM and hybridized onto the flowcell. The hybridized fragments are sequentially amplified, linearized, and end-blocked according to the Illumina Paired-end Sequencing user guide protocol. After hybridization of the sequencing primer, sequencing by synthesis is performed using the HiSeq 2000 sequencer with a 101 cycle protocol according to manufacturer's instructions. The sequenced fragments were denatured with $\mathrm{NaOH}$ using the HiSeq 2000 and the index-primer was hybridized onto the fragments. The index was sequenced with a seven-cycle protocol. The fragments are denatured with $\mathrm{NaOH}$, sequentially amplified, linearized, and end-blocked. After hybridization of the sequencing primer, sequencing by synthesis of the third read is performed using the HiSeq 2000 sequencer with a 101-cycle protocol.

\section{Targeted Chromatin Capture data analysis}

The generated HiSeq 2000 sequencing reads were trimmed if the reads contained the first enzyme restriction recognition site (HindIII for the mouse derived reads and $B g l I$ for the human derived reads) For each read with one or more enzyme recognition sites, the DNA sequence after the $3^{\prime}$ end of the first site was removed, that is, after the trimming procedure the trimmed reads contained and ended with a single restriction recognition site. Subsequently, consecutive bases with a quality score lower than
10 were cut off from the ends of all the reads and the reads that contained less than 12 bases were omitted using Trimmomatic [47]. We used the Burrows-Wheeler Alignment tool (BWA, version 0.6.1) to the whole genome NCBI36/ hg18 assembly for the human derived reads and to $\mathrm{NCBI} 37 / \mathrm{mm} 9$ assembly for the mouse derived reads, using default settings [48]. Aligned reads that localized between two second enzyme recognition sites that did not contain a first enzyme recognition site, that is, all NlaIII-NlaIII restriction fragments were removed using BEDtools [49].

In the alignment, paired reads were removed if one of the reads was not uniquely mapped. Furthermore, paired reads that were a result of a self-ligation event, nondigestion/re-ligation event, or a ligation of identical ends were removed from the analysis, since these paired reads introduce a common bias in chromosome conformation capture techniques [50,51]. The alignments were further processed with SAMtools [48] to generate paired-end Binary Alignment/Map (BAM) files. BEDtools [49] was used to remove reads that overlapped more than one restriction fragment. Interaction matrices were generated from the alignments at a resolution of the restriction fragments and at $40 \mathrm{~kb}$ resolution (using BEDtools on a $40 \mathrm{kbp}$ binned genome). In addition, the human $\mathrm{T} 2 \mathrm{C} 40 \mathrm{~kb}$ binned data were compared to IMR90 $40 \mathrm{~kb} \mathrm{Hi}-\mathrm{C}$ data of the combined replicates [1]. The T2C interaction plots were normalized for capture efficiency of the fragments. For each interaction the number reads of each interaction was normalized through dividing it by the sum of the reads of both fragments involved in the interaction. Similarly, the $\mathrm{T} 2 \mathrm{C}$ plots of the $40 \mathrm{~kb}$ bins were normalized after all the fragments were divided into $40 \mathrm{~kb}$ bins along each chromosome. ChIP-seq and T2C interaction-intersection plots were generated from normalized T2C interaction plots and intersected with fragments that contained a ChIPseq peak signal of the protein of interest. The statistical software package $\mathrm{R}$ (version 3.1.0) was used to generate the interaction plots and to conduct the statistical calculations [52].

\section{ChIP-seq analysis}

Published ChIP-seq datasets $[37,38]$ were obtained and analyzed. MACS [53] was used to identify peaks ( $\mathrm{fdr} \leq 0.01$, peak height $\geq 20$ overlapping reads) to intersect their positions with the interacting fragments obtained from T2C.

\section{Competing interests}

The authors declare that they have no competing interest.

\section{Authors' contributions}

PK, KSW, TAK, and FG designed the experiments. PK, JZ, and KSW carried out the experiments. HJGvdW performed the bioinformatics analysis. NK and RWWB conducted the initial steps of bioinformatics analysis. CEMK and WFJVI carried out the Illumina sequencing. PK, HJGvdW and FG wrote the manuscript. All authors read and approved the final manuscript. 


\section{Acknowledgments}

We thank the members of the FG Laboratory, Argyris Papantonis, Robert-Jan Palstra, and Danny Huylebroeck for discussions and reading the manuscript. PK was supported by grants from EpiGenSys/ERASysBio +/FP7 (NL: NWO, UK: BSRC, D: BMBF). JZ was supported by an NWO ALW grant and KSW by E-RARE/TARGET-CdLS (NL: ZonMW). NK and the grid infrastructure were supported by the BMBF (grant \#01AK803A (German MediGRID), and \#01 IG07015G (Services@MediGRID). HJGvdW was supported by Zenith (93511036) grant from the Netherlands Genomics Initiative (NGI). The work was supported by EpiGenSys/ERASysBio +/FP7 (NL: NWO, UK: BSRC, D: BMBF), the Bluescript EU Integrated Project, the Netherlands Institute for Regenerative Medicine (NIRM), the MEC Booster grant by the Netherlands Genomics Institute (MEC Booster grant) and the KNAW (professorship to FG).

\section{Accession number}

The accession number is SRP042002

\section{Author details}

'Department of Cell Biology, Erasmus MC, Dr. Molewaterplein 50, 3015GE Rotterdam, The Netherlands. ${ }^{2}$ Deutsches Krebsforschungszentrum (DKFZ) \& BioQuant, Im Neuenheimer Feld 280, Heidelberg 69120, Germany. ${ }^{3}$ Center for Biomics, Erasmus MC, Dr. Molewaterplein 50, 3015GE Rotterdam, The Netherlands.

\section{Received: 28 April 2014 Accepted: 28 May 2014}

Published: 16 June 2014

\section{References}

1. Dixon JR, Selvaraj S, Yue F, Kim A, Li Y, Shen Y, Hu M, Liu JS, Ren B: Topological domains in mammalian genomes identified by analysis of chromatin interactions. Nature 2012, 485:376-380

2. Cremer T, Cremer C: Chromosome territories, nuclear architecture and gene regulation in mammalian cells. Nat Rev Genet 2001, 2:292-301.

3. Dillon N, Trimborn T, Strouboulis J, Fraser P, Grosveld F: The effect of distance on long-range chromatin interactions. Mol Cell 1997, 1:131-139.

4. Mueller-Storm HP, Sogo JM, Schaffner W: An enhancer stimulates transcription in trans when attached to the promoter via a protein bridge. Cell 1989, 58:767-777.

5. Jhunjhunwala S, van Zelm MC, Peak MM, Cutchin S, Riblet R, van Dongen JJ, Grosveld FG, Knoch TA, Murre C: The 3D structure of the immunoglobulin heavy-chain locus: implications for long-range genomic interactions. Cell 2008, 133:265-279.

6. Medvedovic J, Ebert A, Tagoh H, Tamir IM, Schwickert TA, Novatchkova M, Sun Q, Veld PJHI't, Guo C, Yoon HS, Denizot Y, Holwerda SJ, de Laat W, Cogne M, Alt FW, Busslinger M: Flexible long-range loops in the VH gene region of the Igh locus facilitate the generation of a diverse antibody repertoire. Immunity 2013, 39:229-244.

7. Bulger $\mathrm{M}$, Groudine M: Functional and mechanistic diversity of distal transcription enhancers. Cell 2011, 144:327-339.

8. Maeda RK, Karch F: Gene expression in time and space: additive vs hierarchical organization of cis-regulatory regions. Curr Opin Genet Dev 2011, 21:187-193.

9. Kolovos P, Knoch TA, Grosveld FG, Cook PR, Papantonis A: Enhancers and silencers: an integrated and simple model for their function. Epigenetics Chromatin 2012, 5:1.

10. Maas SA, Fallon JF: Single base pair change in the long-range Sonic hedgehog limb-specific enhancer is a genetic basis for preaxial polydactyly. Dev Dyn 2005, 232:345-348.

11. Lin YC, Murre C: Nuclear location and the control of developmental progression. Curr Opin Genet Dev 2013, 23:104-108.

12. Splinter E, de Wit E, Nora EP, Klous P, van de Werken HJ, Zhu Y, Kaaij $\sqcup$, van ljcken W, Gribnau J, Heard E, de Laat W: The inactive X chromosome adopts a unique three-dimensional conformation that is dependent on Xist RNA. Genes Dev 2011, 25:1371-1383.

13. Splinter E, Heath H, Kooren J, Palstra RJ, Klous P, Grosveld F, Galjart N, de Laat W: CTCF mediates long-range chromatin looping and local histone modification in the beta-globin locus. Genes Dev 2006, 20:2349-2354.

14. Zuin J, Dixon JR, van der Reijden MI, Ye Z, Kolovos P, Brouwer RW, van de Corput MP, van de Werken HJ, Knoch TA, van ljcken WF, Grosveld FG, Ren B, Wendt KS: Cohesin and CTCF differentially affect chromatin architecture and gene expression in human cells. Proc Natl Acad Sci U S A 2014, 111:996-1001.

15. Deng W, Lee J, Wang H, Miller J, Reik A, Gregory PD, Dean A, Blobel GA: Controlling long-range genomic interactions at a native locus by targeted tethering of a looping factor. Cell 2012, 149:1233-1244.

16. Drissen R, Palstra RJ, Gillemans N, Splinter E, Grosveld F, Philipsen S, de Laat W: The active spatial organization of the beta-globin locus requires the transcription factor EKLF. Genes Dev 2004, 18:2485-2490.

17. Hou C, Dale R, Dean A: Cell type specificity of chromatin organization mediated by CTCF and cohesin. Proc Natl Acad Sci U S A 2010, 107:3651-3656.

18. Lin YC, Benner C, Mansson R, Heinz S, Miyazaki K, Miyazaki M, Chandra V, Bossen C, Glass CK, Murre C: Global changes in the nuclear positioning of genes and intra- and interdomain genomic interactions that orchestrate B cell fate. Nat Immunol 2012, 13:1196-1204.

19. Dekker J, Rippe K, Dekker M, Kleckner N: Capturing chromosome conformation. Science 2002, 295:1306-1311.

20. Tolhuis B, Palstra RJ, Splinter E, Grosveld F, de Laat W: Looping and interaction between hypersensitive sites in the active beta-globin locus. Mol Cell 2002, 10:1453-1465.

21. Hagege H, Klous P, Braem C, Splinter E, Dekker J, Cathala G, de Laat W, Forne T: Quantitative analysis of chromosome conformation capture assays (3C-qPCR). Nat Protoc 2007, 2:1722-1733.

22. Naumova N, Smith EM, Zhan Y, Dekker J: Analysis of long-range chromatin interactions using Chromosome Conformation Capture. Methods 2012, 58:192-203.

23. Stadhouders R, Kolovos P, Brouwer R, Zuin J, van den Heuvel A, Kockx C, Palstra RJ, Wendt KS, Grosveld F, van ljcken W, Soler E: Multiplexed chromosome conformation capture sequencing for rapid genome-scale high-resolution detection of long-range chromatin interactions. Nat Protoc 2013, 8:509-524

24. van de Werken HJ, Landan G, Holwerda SJ, Hoichman M, Klous P, Chachik R, Splinter E, Valdes-Quezada C, Oz Y, Bouwman BA, Verstegen MJ, de Wit E, Tanay A, de Laat W: Robust 4C-seq data analysis to screen for regulatory DNA interactions. Nat Methods 2012, 9:969-972.

25. Simonis $M$, Klous $P$, Splinter $E$, Moshkin $Y$, Willemsen $R$, de Wit $E$, van Steensel $B$, de Laat W: Nuclear organization of active and inactive chromatin domains uncovered by chromosome conformation captureon-chip (4C). Nat Genet 2006, 38:1348-1354.

26. Sexton T, Kurukuti S, Mitchell JA, Umlauf D, Nagano T, Fraser P: Sensitive detection of chromatin coassociations using enhanced chromosome conformation capture on chip. Nat Protoc 2012, 7:1335-1350.

27. Gondor A, Rougier C, Ohlsson R: High-resolution circular chromosome conformation capture assay. Nat Protoc 2008, 3:303-313.

28. Fullwood MJ, Liu MH, Pan YF, Liu J, Xu H, Mohamed YB, Orlov YL, Velkov S, Ho A, Mei PH, Chew EG, Huang PY, Welboren WJ, Han Y, Ooi HS, Ariyaratne PN, Vega VB, Luo Y, Tan PY, Choy PY, Wansa KD, Zhao B, Lim KS, Leow SC, Yow JS, Joseph R, Li H, Desai KV, Thomsen JS, Lee YK: An oestrogenreceptor-alpha-bound human chromatin interactome. Nature 2009, 462:58-64.

29. Dostie J, Dekker J: Mapping networks of physical interactions between genomic elements using 5C technology. Nat Protoc 2007, 2:988-1002.

30. Lieberman-Aiden E, van Berkum NL, Williams L, Imakaev M, Ragoczy T, Telling A, Amit I, Lajoie BR, Sabo PJ, Dorschner MO, Sandstrom R, Bernstein B, Bender MA, Groudine M, Gnirke A, Stamatoyannapoulos J, Mirny LA, Lander ES, Dekker J: Comprehensive mapping of long-range interactions reveals folding principles of the human genome. Science 2009, 326:289-293.

31. Dostie J, Richmond TA, Arnaout RA, Selzer RR, Lee WL, Honan TA, Rubio ED, Krumm A, Lamb J, Nusbaum C, Green RD, Dekker J: Chromosome Conformation Capture Carbon Copy (5C): a massively parallel solution for mapping interactions between genomic elements. Genome Res 2006, 16:1299-1309.

32. Jin F, Li Y, Dixon JR, Selvaraj S, Ye Z, Lee AY, Yen CA, Schmitt AD, Espinoza CA, Ren B: A high-resolution map of the three-dimensional chromatin interactome in human cells. Nature 2013, 503:290-294.

33. Nativio $R$, Wendt $K S$, Ito $Y$, Huddleston JE, Uribe-Lewis $S$, Woodfine $K$ Krueger C, Reik W, Peters JM, Murrell A: Cohesin is required for higherorder chromatin conformation at the imprinted IGF2-H19 locus. PLoS Genet 2009, 5:e1000739.

34. van de Corput MP, de Boer E, Knoch TA, van Cappellen WA, Quintanilla A, Ferrand L, Grosveld FG: Super-resolution imaging reveals three-dimensional 
folding dynamics of the beta-globin locus upon gene activation. J Cell Sci 2012, 125:4630-4639.

35. Palstra RJ, Tolhuis B, Splinter E, Nijmeijer R, Grosveld F, de Laat W: The betaglobin nuclear compartment in development and erythroid differentiation. Nat Genet 2003, 35:190-194.

36. Song SH, Hou C, Dean A: A positive role for NLI/Ldb1 in long-range betaglobin locus control region function. Mol Cell 2007, 28:810-822.

37. ENCODE Project Consortium, Bernstein BE, Birney E, Dunham I, Green ED, Gunter C, Snyder M: An integrated encyclopedia of DNA elements in the human genome. Nature 2012, 489:57-74.

38. Soler E, Andrieu-Soler C, de Boer E, Bryne JC, Thongjuea S, Stadhouders R, Palstra RJ, Stevens M, Kockx C, van ljcken W, Hou J, Steinhoff C, Rijkers E, Lenhard B, Grosveld F: The genome-wide dynamics of the binding of Ldb1 complexes during erythroid differentiation. Genes Dev 2010, 24:277-289.

39. Fraser $P$, Bickmore $W$ : Nuclear organization of the genome and the potential for gene regulation. Nature 2007, 447:413-417.

40. Misteli T: Beyond the sequence: cellular organization of genome function. Cell 2007, 128:787-800.

41. Simonis M, Klous P, Homminga I, Galjaard RJ, Rijkers EJ, Grosveld F, Meijerink JP, de Laat W: High-resolution identification of balanced and complex chromosomal rearrangements by $4 \mathrm{C}$ technology. Nat Methods 2009, 6:837-842.

42. Stadhouders R, van den Heuvel A, Kolovos P, Jorna R, Leslie K, Grosveld F, Soler E: Transcription regulation by distal enhancers: who's in the loop? Transcription 2012, 3:181-186.

43. Li L, Lee JY, Gross J, Song SH, Dean A, Love PE: A requirement for Lim domain binding protein 1 in erythropoiesis. J Exp Med 2010, 207:2543-2550.

44. Li L, Jothi R, Cui K, Lee JY, Cohen T, Gorivodsky M, Tzchori I, Zhao Y, Hayes SM, Bresnick EH, Zhao K, Westphal H, Love PE: Nuclear adaptor Ldb1 regulates a transcriptional program essential for the maintenance of hematopoietic stem cells. Nat Immunol 2011, 12:129-136.

45. Mylona A, Andrieu-Soler C, Thongjuea S, Martella A, Soler E, Jorna R, Hou J, Kockx C, van ljcken W, Lenhard B, Grosveld F: Genome-wide analysis shows that Ldb1 controls essential hematopoietic genes/pathways in mouse early development and reveals novel players in hematopoiesis. Blood 2013, 121:2902-2913.

46. Mukhopadhyay M, Teufel A, Yamashita T, Agulnick AD, Chen L, Downs KM, Schindler A, Grinberg A, Huang SP, Dorward D, Westphal H: Functional ablation of the mouse Ldb1 gene results in severe patterning defects during gastrulation. Development 2003, 130:495-505.

47. Bolger AM, Lohse M, Usadel B: Trimmomatic: a flexible trimmer for Illumina sequence data. Bioinformatics 2014, [Epub ahead of print].

48. Li H, Durbin R: Fast and accurate short read alignment with BurrowsWheeler transform. Bioinformatics 2009, 25:1754-1760.

49. Quinlan AR, Hall IM: BEDTools: a flexible suite of utilities for comparing genomic features. Bioinformatics 2010, 26:841-842.

50. Nagano T, Lubling Y, Stevens TJ, Schoenfelder S, Yaffe E, Dean W, Laue ED, Tanay A, Fraser P: Single-cell Hi-C reveals cell-to-cell variability in chromosome structure. Nature 2013, 502:59-64.

51. van de Werken HJ, de Vree PJ, Splinter E, Holwerda SJ, Klous P, de Wit E, de Laat W: 4 C technology: protocols and data analysis. Methods Enzymol 2012, 513:89-112.

52. R-Core-Team: R: A language and environment for statistical computing. Vienna, Austria: R Foundation for Statistical Computing; 2013 [http://www.r-project.org/]

53. Zhang Y, Liu T, Meyer CA, Eeckhoute J, Johnson DS, Bernstein BE, Nusbaum C, Myers RM, Brown M, Li W, Liu XS: Model-based analysis of ChIP-Seq (MACS). Genome Biol 2008, 9:R137.

doi:10.1186/1756-8935-7-10

Cite this article as: Kolovos et al.: Targeted Chromatin Capture (T2C): a novel high resolution high throughput method to detect genomic interactions and regulatory elements. Epigenetics \& Chromatin 2014 7:10

\section{Submit your next manuscript to BioMed Central and take full advantage of:}

- Convenient online submission

- Thorough peer review

- No space constraints or color figure charges

- Immediate publication on acceptance

- Inclusion in PubMed, CAS, Scopus and Google Scholar

- Research which is freely available for redistribution

Submit your manuscript at www.biomedcentral.com/submit
Ciomed Central 